\title{
Avaliação de políticas públicas de saneamento: o caso do Programa Minas Trata Esgoto
}

\author{
Evaluation of sanitation public policies: the case of "Minas Trata Esgoto" Program
}

\author{
Rafael Caldeira Magalhães', Cynthia Franco Andrade², José Neuciano de Oliveira ${ }^{3}$, Elias Sete Manjate ${ }^{4}$ \\ 1,3,4 Doutorando do Programa de Pós-Graduação em Saneamento, Meio Ambiente e Recursos Hídricos, Universidade Federal de Minas Gerais, \\ Belo Horizonte, MG, Brasil. E-mail do autor principal: ambienterfl@gmail.com \\ ${ }^{2}$ Mestre do Programa de Pós-Graduação em Saneamento, Meio Ambiente e Recursos Hídricos, Universidade Federal de Minas Gerais, \\ Belo Horizonte, MG, Brasil
}

\begin{abstract}
Resumo
No ano de 2006, quando aproximadamente 97\% dos 853 municípios do Estado de Minas Gerais lançavam os esgotos brutos nos corpos d'água, foi publicada a Deliberação Normativa COPAM nº 96/2006, sobre a implantação de sistema de tratamento de esgotos sanitários em todos os municípios. Com isso, no mesmo ano, implantou-se o Programa Minas Trata Esgoto com o objetivo de realizar a gestão estratégica da implantação desses sistemas, monitorando o aumento do percentual de esgoto tratado no Estado por meio do processo de licenciamento ambiental das ETE. Tal monitoramento possui muitas fragilidades e, para tentar minimizá-las, o Programa realiza campanhas de vistoria, por bacia hidrográfica, para avaliação da situação real do esgotamento sanitário dos municípios. O presente trabalho consiste em uma avaliação ex-post do início do Programa até o ano de 2012, tendo em vista o ciclo de políticas públicas. A implementação ocorreu da forma top-down, sem a consideração de alguns condicionantes sistêmicos importantes para o alcance dos objetivos, ainda assim, nesse período Minas Gerais avançou no enorme desafio da universalização do esgotamento sanitário.
\end{abstract}

Palavras-chaves: : Esgotamento sanitário. Políticas públicas. Minas Trata Esgoto.

\begin{abstract}
In 2006, when approximately $97 \%$ of 853 Municipalities of Minas Gerais discharged their raw sewage in the rivers was published Normative Resolution COPAM n $n^{\circ}$ 96/2006 on the implementation of systems of sewage treatment involving all Municipalities. Also in 2006 was implemented the program entitled Minas Treat Sewage Program (MTSP) in order to accomplish strategic management by monitoring the increase of the percentage of treated sewage in the Minas Gerais State through licensing environmental processes of wastewater treatment plants. This monitoring process has certain weaknesses, and in order to reduce them the program conducts a survey in each watershed to assess the real situation of sewerage in the municipalities and to reduce weaknesses. The present work is an ex-post evaluation from the beginning of the program until 2012 considering the public policy cycle. On the other hand, the implementation of the program took place without consideration of some important systemic conditions related to the achievement their objectives. In fact, from 2006 to 2013 through the MTSP the state of Minas Gerais increased in terms of the universalization sewerage
\end{abstract}

Keywords: Sewerage, Public policy, Minas Treat Sewage Program. 


\section{INTRODUÇÃO}

No Brasil, até o ano de 2007, o saneamento abrangia somente os serviços de abastecimento de água e esgotamento sanitário, sendo que os investimentos no primeiro foram superiores por décadas. Tal fato acarretou em índices de coleta e tratamento de esgotos baixos ainda nos dias de hoje (HELLER et al., 2012).

No Estado de Minas Gerais, a trajetória do saneamento não foi distinta a do Brasil. No ano de 2006, dos 853 municípios do Estado, em torno de 97\% lançavam os esgotos brutos nos corpos d'água, mesmo sendo uma prática proibida (MINAS GERAIS, 2006). O lançamento de esgotos domésticos sem tratamento em corpos d'água pode causar impactos ao meio ambiente, danos à saúde pública, conflitos pelo uso da água, havendo ainda a possibilidade de ocorrência de maus odores e desvalorização de áreas.

No ano de 2006, com o objetivo de reduzir a poluição das águas e melhorar a qualidade de vida da população, o Governo de Minas Gerais, por meio da Secretaria de Estado de Meio Ambiente e Desenvolvimento Sustentável (SEMAD), mais especificamente o Conselho Estadual de Política Ambiental (COPAM), deliberou pela implantação de sistema de tratamento de esgotos sanitários em todos os 853 municípios, convocando-os ao licenciamento ambiental, divididos em 7 (sete) grupos, conforme a Deliberação Normativa (DN) COPAM nº 96/2006 e, posteriormente, a DN COPAM n ${ }^{\circ}$ $128 / 2008$.

Nesse contexto, ainda no ano de 2006 foi implantado pela Fundação Estadual do Meio Ambiente (FEAM), vinculada à SEMAD, o Programa Minas Trata Esgoto (PMTE), com o objetivo de realizar a gestão estratégica da implantação de sistemas de tratamento de esgotos no Estado. De 2006 a 2012 o PMTE vem apresentando resultados, bem como publicações em decorrência de suas atividades de apoio aos municípios no atendimento às Deliberações. Algumas atividades podem ser citadas, como seminários, publicação de cartilhas com orientações, visitas e vistorias técnicas e mobilização de agentes municipais para o cumprimento dos prazos. Além disso, o Programa monitora o aumento do percentual de esgoto tratado no Estado por meio do processo de licenciamento das Estações de Tratamento de Esgotos (ETE) por município e seus respectivos percentuais de população municipal atendida (MINAS GERAIS, 2010).

A avaliação dos resultados do Programa tem sido realizada pela FEAM, a qual elabora relatórios anuais de progresso e os disponibiliza ao público.

A avaliação de políticas e programas governamentais tem assumido grande relevância para as funções de planejamento e gestão governamentais nas últimas décadas, pois pode subsidiar o planejamento e a formulação das intervenções, o acompanhamento de sua implementação, suas reformulações e ajustes, assim como as decisões sobre a manutenção ou interrupção das ações. É um instrumento importante para a melhoria da eficiência do gasto público, da qualidade da gestão e do controle sobre a efetividade da ação do Estado, bem como para a divulgação de resultados de governo. Nesse sentido, cresce a importância do estudo das políticas públicas, que deve abarcar desde a análise dos motivos que tornam necessária determinada intervenção, até seus resultados alcançados (CUNHA, 2006; MENEGUIN e FREITAS, 2013).

Cohen e Franco (2004) consideram que tais avaliações podem ser classificadas segundo vários critérios, como o agente que as realiza (externa, interna, mista e participativa), a natureza (formativa e somativa), o momento da realização (ex-ante e ex-post) ou os tipos de problemas ou perguntas (de processos ou de impactos). Já Hogwood e Gunn (1984) distingue sete tipos de análise política que abrange um amplo espectro que vai desde os estudos descritivos (análise do conteúdo da política) até os francamente normativos (defesa de políticas).

Políticas públicas, segundo Belloni (2000), podem ser definidas como um conjunto de orientações e ações de um governo com vistas ao alcance de determinados objetivos. É uma ação intencional do Estado junto à sociedade. Assim, por ser voltada para a sociedade e envolver recursos sociais, toda política pública deve ser sistematicamente avaliada do ponto de vista de sua relevância e adequação às necessidades sociais, além de abordar os aspectos de eficiência, eficácia e efetividade das ações empreendidas.

Existe uma diferença entre o conceito mais abrangente de política pública, de um programa e um projeto. O programa é o desdobramento de uma política e o projeto é uma unidade de menor ação. 
Existem diversos modelos explicativos para as diferentes etapas ou fases das políticas públicas. Trata-se de um esforço para explicar a difícil interação de intenções (constituídas na fase de formulação de políticas) e ações (presentes na fase de implementação). Trata-se ainda de discutir a relação que se estabelece entre atores governamentais e atores não governamentais no processo de "fazer política" (KERBAUY, 2004).

O presente trabalho tem como objetivo avaliar o PMTE, no período de 2006 a 2012, por meio da identificação e discussão dos pontos passíveis de melhoria e redirecionamento do Programa, contribuindo para a otimização do seu alinhamento com as políticas públicas de saneamento de âmbitos federal e estadual.

\section{METODOLOGIA}

O presente trabalho consiste de uma pesquisa documental, do período de 2006 a 2012, com o levantamento de dados secundários em relação à implementação e aos resultados do PMTE junto a documentos disponibilizados pela FEAM ao público e pesquisa de trabalhos científicos sobre o tema. Além disso, foram realizadas pesquisas bibliográficas para o aprofundamento conceitual do modelo em análise.

Há diferentes modelos de programas e políticas públicas, como incrementalismo, ciclo de política pública, garbage can, coalizão de defesa, arenas sociais, modelo de equilíbrio interrompido ou path dependence. Para a avaliação do PMTE, considerou-se o ciclo de política como o mais adequado a ser analisado, sendo baseado na definição de agenda, identificação de alternativas, avaliação das opções, seleção das opções, implementação, avaliação e extinção (SECCHI, 2010).

A partir das classificações de Cohen e Franco (2004), definiu-se a avaliação realizada no presente estudo como externa, de natureza somativa, ex-post e com foco nos impactos do PMTE.

Para a avaliação dos tópicos do ciclo de política no PMTE, fez-se uso principalmente dos Relatórios de Progresso referentes aos anos de 2009, 2010, 2011 e 2012, elaborados pela FEAM.

Além disso, as publicações realizadas sobre o tratamento de esgotos de quatro bacias hidrográficas contempladas pelo Programa foram utilizadas como exemplos da atuação em Minas Gerais. Na bacia federal do rio São Francisco foram verificadas as condições do esgotamento sanitário nas bacias do rio das Velhas, Paraopeba e Pará, e na bacia federal do rio Doce, a situação da bacia do rio Piracicaba.

\section{RESULTADOS E DISCUSSÃO}

No modelo de ciclo de políticas, prevalece a ideia de que uma política se inicia a partir da percepção de problemas, passa por um processo de formulação de propostas e decisão, segue sendo implementada, para enfim ser avaliada e dar início a um novo processo de reconhecimento de problemas e formulação de política (SOUZA, 2006).

A ideia de ciclo da política talvez seja a perspectiva mais corrente e compartilhada nos estudos atuais de política, com grande parte dos estudos fazendo uma análise por momentos ou fases do processo político. Uma grande contribuição do modelo é a possibilidade de percepção de que existem diferentes momentos no processo de construção de uma política, apontando para a necessidade de se reconhecer as especificidades de cada um destes momentos, possibilitando maior conhecimento e intervenção sobre o processo político. Por outro lado, ocorre a desvantagem da inevitável fragmentação que a ideia de fases provoca em qualquer análise a ser empreendida (BAPTISTA e REZENDE, 2011).

Nessa perspectiva, o ciclo de políticas não pode ser concebido como um processo simples e linear, mas sim como um processo dinâmico (CAVALCANTI, 2006), o que é avaliado a seguir em todo o processo do PMTE, da definição de agenda à extinção.

\subsection{Identificação de problemas e estabelecimento da agenda}

Na perspectiva do ciclo, de acordo com Baptista e Rezende (2011), o primeiro passo no desenvolvimento de uma política ou programa é o reconhecimento de um problema como de relevância pública. Assim, os problemas constituem o ponto de partida para a geração de uma política pública. 
Kingdon (1984) afirma que tais problemas se apresentam de forma distinta e ganham de diferentes formas a atenção do governo. Assim, denominou Agenda a lista de assuntos e problemas sobre os quais o governo e pessoas ligadas a ele concentram sua atenção em um determinado momento. $\mathrm{O}$ autor conclui que a entrada de novos problemas na agenda decisória não é produzida por um processo necessariamente incremental, mas resultado de uma combinação de fluxos independentes que atravessam as estruturas de decisão - o fluxo de problemas, o fluxo de soluções e alternativas e o fluxo da política.

A identificação do problema que $97 \%$ dos municípios mineiros lançavam os esgotos brutos nos corpos d'água, mesmo sendo uma prática proibida, pode ser considerada como uma entrada na agenda por um fluxo de problemas, que remete a identificação de um problema por dados quantitativos ou por crises, por exemplo. A identificação e a entrada na Agenda contribuem para a construção de argumentos em favor de uma política que busque resolver tais questões, que, no caso, acarretou na DN COPAM n ${ }^{\circ}$ 96/2006 e, consequentemente, no PMTE.

De acordo com Secchi (2010), um problema público pode estar presente por muito tempo, mas não receber suficiente atenção porque a coletividade aprendeu a conviver com ele, como exemplo, o autor cita a favelização das periferias das grandes cidades.

Durante séculos a humanidade vem lançando suas excretas em corpos d'água e, somente em 2006 surge o PMTE, o que demonstra que a população mineira convivia com a falta de tratamento de esgoto e, de fato, por um longo período esta situação não afetava de maneira significativa os usos da água, até se tornar uma prática insustentável nas últimas décadas. Porém, ainda assim, 2006 parece tardio para a identificação do problema e estabelecimento da agenda. O que pode explicar a demora do processo é a clara prioridade brasileira na universalização do abastecimento de água, que consequentemente aumenta a quantidade de esgoto, mas não investe na mesma proporção.

\subsection{Formulação da política}

A formulação da política passa pelo estabelecimento de objetivos e estratégias. Um mesmo objetivo pode ser alcançado de várias formas, por diversos caminhos, podendo ser feito com suporte de três técnicas: projeções (observação de tendências), predições (uso de teorias ou analogias) e conjecturas (juízos de valor) (SECCHI, 2010).

Lowi $(1964 ; 1972)$ define que a formulação de políticas públicas pode assumir quatro formatos. Nas políticas distributivas, as decisões são tomadas pelo governo, que desconsideram a questão dos recursos limitados, gerando impactos mais individuais do que universais, ao privilegiar certos grupos sociais ou regiões, em detrimento do todo. O segundo é o das políticas regulatórias, que são mais visíveis ao público, envolvendo burocracia, políticos e grupos de interesse. O terceiro é o das políticas redistributivas, que atinge maior número de pessoas e impõe perdas concretas e no curto prazo para certos grupos sociais, e ganhos incertos e futuro para outros. O quarto é o das políticas constitutivas, que lidam com procedimentos.

Kerbauy (2002) destaca que existem outras formas de análise da formulação de políticas públicas: racionalidade econômica, racionalidade político-sistêmica e formulação responsável. Segundo a autora, na formulação de política pública pela racionalidade econômica o critério de escolha da política é de economia do bem estar social sem entrar no julgamento de valores. Já a racionalidade políticosistêmica existe acordo entre os atores do jogo do poder. A sociedade e os decisores aceitam o que é viável e o que surgem do labirinto político, não questionando a responsabilidade moral das políticas. Finalmente, a formulação responsável sujeita o processo decisório ao escrutínio público, englobando considerações sobre igualdade, liberdade e democracia.

O PMTE, conforme observado nos relatórios de progresso de 2009 a 2012, foi motivado pelo desafio de diminuir os problemas relacionados com os recursos hídricos e as precárias condições de saúde, especialmente nas periferias das grandes e médias cidades e nos municípios com menos de 20 mil habitantes. O objetivo principal do Governo de Minas Gerais foi de universalizar o serviço de esgotamento sanitário no Estado, através da gestão estratégica. Os objetivos específicos foram de apoiar os municípios na regularização ambiental; fortalecer o conceito de saneamento no âmbito da prevenção; e estabelecer incentivos fiscais (ICMS Ecológico) para os municípios que atenderem aos critérios do Programa. Ressalta-se uma enorme limitação tanto no que se refere à formulação quanto da implementação da política pública, onde os objetivos do PMTE não foram os mesmos nos relatórios publicados pelo Governo do Estado de Minas, assim como os incentivos fiscais não são operaciona- 
lizados no âmbito do Programa.

Os objetivos foram desenhados através de projeções envolvendo sete grupos de municípios no contexto da regularização ambiental, que consiste da autorização ambiental de funcionamento (AAF), licença prévia (LP), de instalação (LI) e operação (LO), no período de 2008 à 2017. O Programa foi focado para a população urbana, conforme pode ser observado na Tabela 1.

Tabela 1 - Grupo de municípios para a atuação do Programa Minas Trata Esgotos.

\begin{tabular}{|c|c|c|c|}
\hline Grupos & Pop urbana (IBGE, 2000) & $\begin{array}{l}\text { Número de } \\
\text { municípios }\end{array}$ & $\begin{array}{l}\text { \% pop urbana } \\
\text { MG }\end{array}$ \\
\hline 1 & Pop. maior que $150 \mathrm{mil}$ & 13 & 39,4 \\
\hline 2 & $\begin{array}{l}\text { Pop. entre } 30 \text { mil e } 150 \text { mil com índice de coleta de esgoto maior } \\
\text { que } 70 \%\end{array}$ & 20 & 9,7 \\
\hline 3 & $\begin{array}{l}\text { Pop. entre } 50 \text { mil e } 150 \text { mil com índice de coleta de esgoto menor } \\
\text { que } 70 \%\end{array}$ & 26 & 13,3 \\
\hline 4 & $\begin{array}{l}\text { Pop. entre } 30 \text { mil e } 50 \text { mil com índice de coleta de esgoto menor } \\
\text { que } 70 \%\end{array}$ & 22 & 5,8 \\
\hline 5 & Municípios Estrada Real & 4 & 0,4 \\
\hline 6 & Pop. entre 20 e 30 mil & 33 & 5,3 \\
\hline 7 & Pop. menor que 20 mil hab & 735 & 26,3 \\
\hline
\end{tabular}

Fonte: Adaptado de Minas Gerais (2006)

Conforme pode ser observado na Tabela 1, os grupos de municípios possuem enorme heterogeneidade quanto à sua divisão. Ao considerar faixas de população como única variável para caracterizar todos os municípios de Minas Gerais, desprezou-se critérios de renda, dimensão social e ambiental. Ao passo que o grupo 1 possui $39,4 \%$ da população urbana, os municípios da Estrada Real apenas representam $0,4 \%$. Ressalta-se que a Estrada Real corta grande parte do Estado de Minas Gerais através de 162 municípios (MINAS GERAIS, 2013a). Cabe ressaltar que não há entendimento por parte do próprio Governo de Minas Gerais na definição de critérios dos grupos de municípios atendidos pelo PMTE.

O PMTE, considerando a visão teórica de Lowi (1964; 1972), enquadra-se no contexto de políticas regulatórias, pois sua concepção está baseada principalmente numa visão burocrática para equacionar o problema de esgotamento sanitário de Minas Gerais, onde, para atingir seus objetivos, priorizou-se estabelecer metas apoiadas no processo de licenciamento ambiental, ou seja, um instrumento legal da política ambiental brasileira. Os atores sociais envolvidos são formados pelos municípios e pelo Estado, que, quando colocados na balança, geram desequilíbrios de acordo com os interesses políticos, econômicos e sociais.

Já no contexto teórico colocado por Kerbauy (2002), observa-se que o PMTE está inserido no modelo de formulação de política pública baseado na racionalidade econômica, pois não se observou grandes processos de negociação da política. Conforme observado nos relatórios e dados secundários obtidos na análise deste trabalho, a formulação da política foi imposta aos municípios como uma necessidade de transferência de responsabilidade do Estado de Minas Gerais com uma legitimação do COPAM, o qual não inseriu os critérios necessários para uma visão mais democrática do processo.

\subsection{Tomada de decisão}

A tomada de decisão ou processo decisório é o momento em que os interesses dos atores são equacionados e as intenções (objetivos e métodos) de enfrentamento de um problema público são explicitados. (SECCHI, 2010).

Para Kerbauy (2004), no Brasil a institucionalização do campo das políticas públicas é recente, detendo-se, basicamente, em três áreas: i) regime político, instituições políticas ou o Estado Brasileiro em termos de seu traço constitutivo (patrimonialismo, clientelismo ou autoritarismo) para analisar políticas específicas; ii) políticas setoriais que combinam a análise do processo político com a análise 
dos problemas internos às próprias áreas setoriais.; e iii) políticas públicas de corte social: comparação com o Estado de Bem Estar Social - processos de acumulação e legitimação - análise da especificidade do sistema de proteção social.

O processo decisório é o produto do livre jogo de influência e de poder entre os grupos de pressão organizados que defendem interesses quase sempre individuais declarados publicamente. Quanto maior o alcance da pressão sobre os decisores, é mais provável que a decisão seja favorável ao grupo que a exerce (KERBAUY, 2004). A escolha se dá entre as várias alternativas em ação. Normalmente, precedem ao ato de decisão, processos de conflito e de acordo, envolvendo, pelo menos, os atores mais influentes na política e na administração.

As decisões sobre a formulação da política pública ambiental (nela se incluem as de esgotamento sanitário) são do COPAM, que possui representantes do Poder Público e da Sociedade Civil. Ressalta-se que o PMTE é uma política pública que envolve diretamente os municípios e estes, por sua vez possuem representação limitada no Conselho, com apenas uma representação com direito a voto. São 18 representantes do Poder Público (reforça-se que apenas uma representação de municípios) e 18 representantes da sociedade civil, totalizando 36 conselheiros.

A DN n ${ }^{\circ}$ 96/2006 do COPAM foi um processo decisório baseado em fundamento normativo, sem consideração sobre a situação técnica dos municípios quanto aos procedimentos para a regularização ambiental. Simplesmente foram definidos os municípios com as datas limites para a obtenção de licenças.

Observa-se que não houve uma discussão participativa baseada nas dificuldades sociais, econômicas, culturais e ambientais dos municípios. Além disso, o COPAM não disponibilizou a ata de deliberação para que houvesse um entendimento sobre o processo, ou seja, os meios para a resolução de determinadas necessidades sociais.

\subsection{Implementação do Programa}

A implementação em políticas públicas pode ser considerada como um processo de interação entre a determinação de objetivos e as ações empreendidas para atingi-los. Consiste no planejamento e na organização do aparelho administrativo e dos recursos humanos, financeiros, materiais e tecnológicos necessários para realizar uma política (OLIVEIRA, 2006).

A implementação do PMTE foi feita basicamente pela forma top-down (NAJAN, 1995), em que o Governo do Estado, através do COPAM, decidiu por implantar o Programa sem a participação

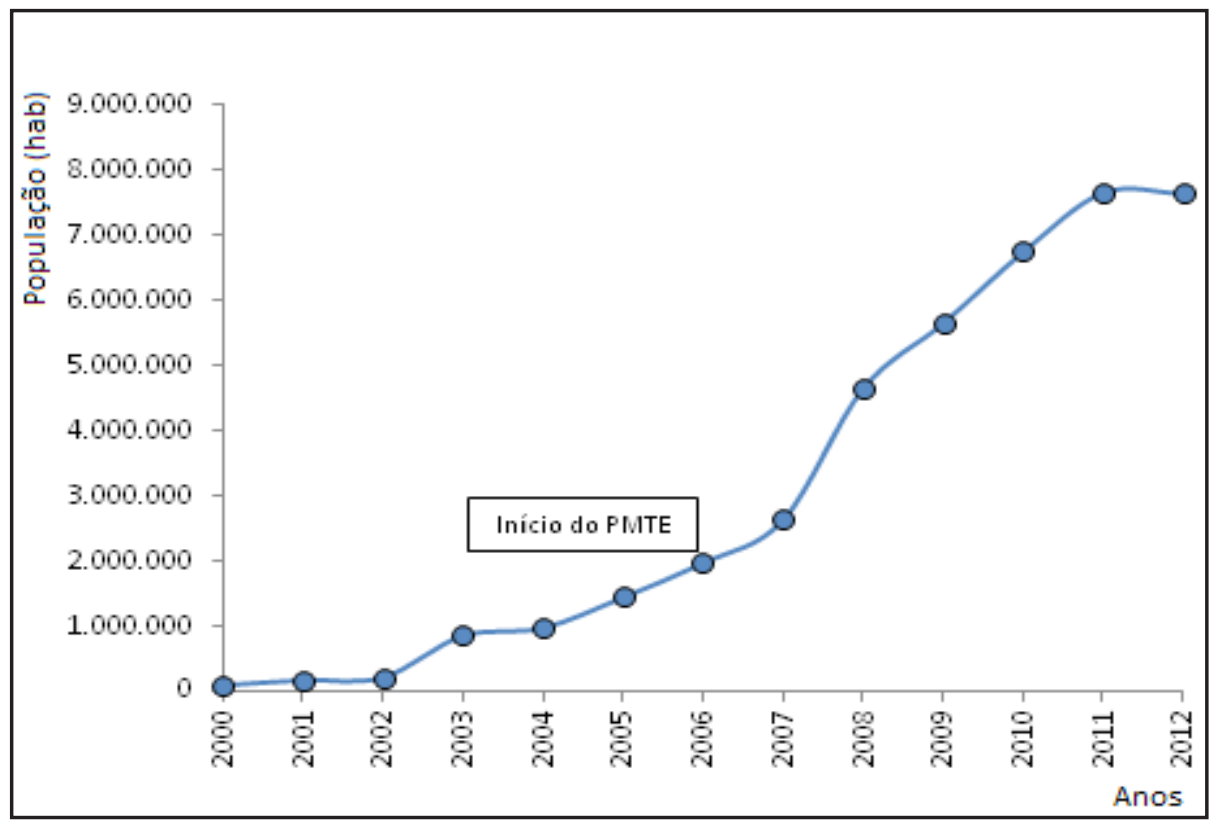

Figura 1 - População urbana atendida por sistemas de tratamento de esgoto sanitários, com a devida regularização ambiental, considerando-se a capacidade das Estações de Tratamento de Esgotos (ETE).

Fonte: Adaptado de Minas Gerais (2013) 
efetiva dos municípios mineiros e da população beneficiada pelos serviços. A partir da promulgação da DN COPAM n ${ }^{\circ}$ 96/2006, e posteriormente da $\mathrm{DN} \mathrm{n}^{\circ}$ 128/2008, os municípios mineiros passaram a ter um marco legal que estabeleceu metas e prazos diferenciados para implantação e regularização ambiental dos sistemas de tratamento de esgoto municipais, de acordo com o índice de cobertura a ser atingido e com a população de cada município, com exceção de alguns municípios que fazem parte da rota da estrada real.

No ano de 2006 o Programa começou a ser implementado a partir do auxílio da FEAM aos municípios na gestão estratégica da implantação de sistemas de tratamento de esgotos, por meio da proposição de diretrizes de adequação e inovação, no apoio ao licenciamento dos empreendimentos e no atendimento à legislação ambiental vigente.

Desde o início da implementação do Programa, a população do Estado atendida pelos sistemas de tratamento de esgotos regularizados cresceu de 1.980.696 habitantes em 2006 para 7.660 .485 habitantes em 2012, ano da última avaliação dos resultados do Programa (Figura 1) (MINAS GERAIS, 2013b). Esses resultados mostram que a implementação do Programa teve êxito na elevação da população atendida por serviços de tratamento de esgoto regularizados no Estado, porém alguns fatores de suma importância para o aumento da população atendida no Estado devem ser considerados, como o início da operação da ETE Onça em 2007 na cidade de Belo Horizonte, com capacidade instalada para atender cerca de 1.030.000 habitantes (MINAS GERIAS, 2013c), que indica que o aumento da população atendida por ETE regularizadas não foi totalmente influenciado pelo PMTE.

Além de não considerar esses fatores, foi observado que a população do Estado atendida pelos serviços em 2012 foi somente de aproximadamente $57 \%$ da população que realmente deveria ser atendida com base na DN COPAM n ${ }^{\circ} 128 / 2008$ (13.399.489 hab.), inferindo-se que o Programa não atingiu as metas estabelecidas e apresentou algumas falhas na sua implementação.

Dentre alguns fatores que contribuíram para que o Programa apresentasse falhas na sua implementação, destaca-se que a FEAM forneceu aos municípios apenas apoio institucional e disponibilizou um manual de captação de recursos junto ao Governo Federal para a implantação e regularização dos sistemas de tratamento, sem considerar, durante a fase de elaboração da política, o montante de recursos necessários para execução das obras nos prazos estabelecidos pela DN COPAM n ${ }^{\circ}$ 128/2008. Dessa forma, municípios que não possuíam recursos próprios suficientes para a construção dos sistemas com todos os requisitos necessários para que fossem licenciados, tiveram que solicitar recursos nas esferas estadual e federal, o que pode ter atrasado ou inviabilizado a conclusão das obras em tempo hábil, devido aos trâmites burocráticos necessários para obtenção desses recursos e ao modelo federalista brasileiro de hierarquização dos investimentos nas políticas sociais em níveis estadual e municipal (ARRETCHE, 2002).

É muito importante estabelecer o entendimento sobre o tema do federalismo nas políticas públicas de saneamento, especialmente focalizando problemas de coordenação e autonomia. Com a Constituição de 1988 e a Lei Federal de Saneamento Básico nº 11.445/2007, o município, como titular dos serviços, tornou-se um importante elemento no planejamento e implementação das políticas públicas de saneamento. No entanto, ao passo que esta política foi descentralizada, os recursos para o seu financiamento não foram e não são distribuídos de forma equânime, favorecendo impasses de gestão que ultrapassam as responsabilidades do poder local.

Observa-se a necessidade de promover, por parte do próprio Governo Federal, movimentos de descentralização a partir da valorização da cooperação entre os entes federados, inclusive os Governos Estaduais (neste ponto a Companhia de Saneamento de Minas Gerais - COPASA possui fundamental importância de compreender que seus serviços são de utilidade pública e não privada), numa lógica de solidariedade, em detrimento do individualismo institucional e localista. Para Arretche (2004) a política de saneamento, por ter um financiamento baseado fundamentalmente no Governo Federal, permitiu à União definir unilateralmente as regras para obtenção de empréstimos, endurecendo as condições para sua concessão e, portanto, desfinanciando os governos subnacionais.

Outro fator que contribuiu para falhas na implementação e no cumprimento dos objetivos do PMTE foi o estabelecimento de prazos diferenciados para regularização ambiental e implantação dos sistemas somente de acordo com a população do município, não levando em consideração as peculiaridades regionais e municipais. Dessa forma, alguns fatores como o nível de desenvolvimento tecnológico e econômico dos municípios não foram considerados durante a implementação do Programa, o que 
levou ao não cumprimento ou ao cumprimento parcial das metas por grande parte dos municípios.

Nesse sentido, municípios que apresentam uma população elevada, mas que não possuem capacidade técnica e financeira para atendimento das metas do Programa estabelecidas para o ano de 2012, tiveram um prazo reduzido para se adequarem as exigências das deliberações normativas em relação a municípios com população menor, porém mais desenvolvidos tecnologicamente e com economia fortemente influenciada por atividades como turismo, mineração e agropecuária, os quais terão, em sua maioria, até 2017 para cumprirem as metas do PMTE.

Tais fatores conectam-se com o conceito de condicionantes sistêmicos, onde Heller e Castro (2007) acreditam que, ao examinar fatores e processos que apesar de externos às atividades ligadas aos serviços de água e esgoto, exercem influência significativa na moldagem da organização e funcionamentos deles, e em algumas situações, até em seu desenvolvimento original, analisa, para além dos já conhecidos condicionantes sistêmicos (ou seja, os fatores físicos naturais, aspectos econômicofinanceiros, processos demográficos e geográficos), outros processos historicamente minimizados, como a dimensão social.

A análise torna-se mais complexa ao considerarmos as diferenças nos consumos de água entre regiões, cidades ou grupos sociais, caso em que muitas vezes, fatores como as desigualdades sociais estruturais são mais importantes para explicar as assimetrias na abrangência e qualidade dos serviços, ou as diferenças nos hábitos de consumo, do que, por exemplo, restrições climáticas ou tecnológicas (CASTRO, 2013, P. 55).

\subsection{Avaliação do Programa}

A avaliação em políticas públicas pode ser considerada como o exame sistemático e objetivo de um projeto ou programa, finalizado ou em curso, que contemple seu desempenho, implementação e resultados, tendo em vista a determinação de sua eficiência, efetividade, impacto, sustentabilidade e relevância de seus objetivos (COSTA; CASTANHAR, 2003).

O PMTE tem sua avaliação feita a partir do atendimento ou não das metas de regularização ambiental e de implantação de sistemas de esgotamento sanitário para cada grupo de municípios de acordo com os índices de cobertura e os prazos estabelecidos pelas deliberações normativas COPAM $n^{\circ} 96 / 2006$ e n ${ }^{\circ} 128 / 2008$.

Dessa forma, o PMTE avalia somente se os grupos de municípios atenderam aos requisitos básicos das deliberações, que se limita a regularização ambiental dos sistemas nos prazos e nos índices de cobertura estabelecidos para sua categoria (MINAS GERAIS, 2011a), não avaliando a qualidade e a eficiência do processo de tratamento de esgoto implantado, conforme a Figura 2. Observa-se ainda que sistemas com LO ou AAF vencidas são considerados como sem ações, ocorrendo um aumento da categoria.

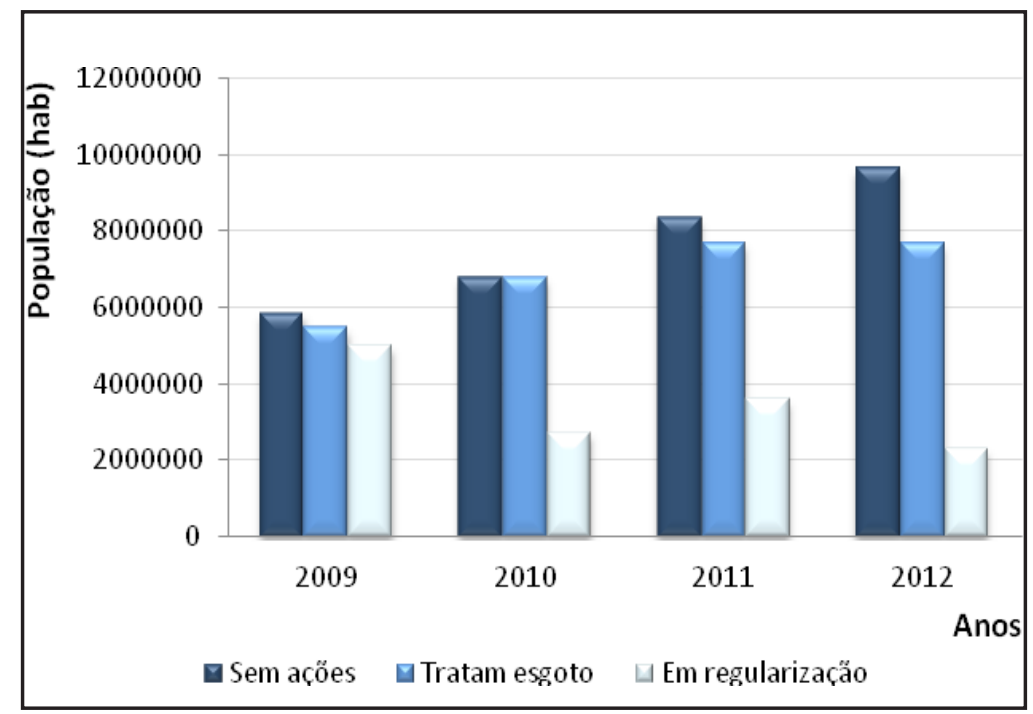

Figura 2 - População de municípios sem regularização, em processo de regularização e com regularização ambiental para sistemas de tratamento de esgotos no Estado de Minas Gerais.

Fonte: Minas Gerais (2013). 
Nesse sentido, a FEAM constatou a fragilidade dessa metodologia de avaliação e para minimizá-la elabora o Plano para Incremento do Percentual de Tratamento de Esgotos Sanitários nas Bacias Hidrográficas (PITE), que realiza vistorias e visitas de campo, divididas por bacias hidrográficas, onde são obtidos dados primários em relação a diversos itens, como: titularidade, condições da instalação, tipo de tratamento, vazão afluente, população atendida, entre outros. Após os trabalhos de campo, é elaborado o plano da bacia, contendo o diagnóstico e prognóstico da situação do sistema de cada município e diretrizes visando ao incremento do percentual de tratamento de esgotos sanitários.

Até o mês de junho de 2014, quatro bacias hidrográficas estaduais tiveram seus Planos finalizados, são elas: das Velhas, Paraopeba, Pará e Piracicaba. As bacias do rio Mogi-Guaçu e Pardo e do rio Piranga estão com os Planos em andamento.

De maneira geral, os Planos possuem uma enorme quantidade de dados sobre os sistemas de esgotamento sanitário de cada município, e das bacias como um todo, e por isso tornam-se importantes instrumentos de gestão e pesquisa de dados.

A primeira bacia a ser contemplada pelo PMTE foi a bacia hidrográfica do rio das Velhas, que está localizada na bacia hidrográfica do rio São Francisco (BHSF) e abrange 51 municípios (MINAS GERAIS, 2011b). Verificou-se que a conjuntura dos serviços de esgotamento sanitário na bacia é diversificada, variando no percentual de atendimento à população, no número de ETE em operação, no tipo de tratamento dado aos esgotos coletados, na concessão dos serviços e na situação dos municípios perante as DN COPAM no 96/2006 e n ${ }^{\circ} 128 / 2008$.

As ETE foram classificas em cinco classes nomeadamente: estação em boas condições de operação; estações em condições precárias de operação, estação em obras, estação fora da operação e estação em fase de projeto. Contudo, o Plano não aponta medidas concretas para a operacionalização das estações fora de operação e a sua devida regularização, uma vez ter-se verificado precariedade de alguns municípios quanto aos seus sistemas de esgotamento sanitário (MINAS GERAIS, 2011b).

Em relação à prestação dos serviços de tratamento de esgotos observou-se que em $58,70 \%$ dos municípios, os sistemas de tratamento de esgotos estão sob a responsabilidade da prefeitura, atendo uma população apenas de $7,57 \%$, percentual que pode ser considerado insignificante em relação ao número das pessoas atendidas pela COPASA (MINAS GERAIS, 2011b).

No ano de 2011 foi a vez da bacia hidrográfica do rio Paraopeba (BHRP), também localizada na BHSF, a ser contemplada com as visitas a campo e o Plano. Além de ser uma bacia de grande importância para a Região Metropolitana de Belo Horizonte (RMBH) - com mais de 2 milhões de pessoas, distribuídas em 48 municípios (MINAS GERAIS, 2011b) - a BHRP é adjacente à BHRV - Bacia Hidrográfica do Rio das Velhas, o que a torna de grande interesse para a continuidade dos trabalhos realizados pelo PMTE.

Analisando o conteúdo do Plano da BHRP observa-se que não é explícita a relação do Plano com o PMTE, sendo informado apenas que o estudo faz parte do Programa. Da mesma forma, os objetivos do Plano não são apresentados de maneira clara. A metodologia utilizada é frágil, pois os dados primários utilizados são informações autodeclaradas pelos municípios, podendo não retratar a realidade local. Os autores reconhecem essa fragilidade e afirmam ter buscado confirmar a veracidade dos dados fornecidos (MINAS GERAIS, 2011b).

Alguns erros conceituais são encontrados no conteúdo do Plano, como no diagnóstico quando os autores referem-se à titularidade dos serviços de esgotamento sanitário prestados e afirmam que a COPASA é a titular em 13 municípios. O correto seria informar que a COPASA presta os serviços em 13 municípios, mas a titularidade é dos municípios, ou local, conforme a Lei $\mathrm{n}^{\circ}$ 11.445/2007 (BRASIL, 2007).

Em relação à regularização ambiental, os autores do Plano da BHRP (MINAS GERAIS, 2011c) apresentam que de 48 ETEs avaliadas nas vistorias, 42 estão sem licença ambiental ou com a mesma vencida. Tal constatação demonstra que a análise do PMTE sobre o tratamento de esgoto, a partir somente das ETE com AAF ou LO, pode acarretar em índices de tratamento de esgoto distantes da realidade do Estado. Das 42 ETE sem regularização ambiental, os autores não informam quantas estão em condições boas ou precárias, contribuindo de toda forma para o tratamento de esgoto da bacia.

Além disso, como informado pelos autores (MINAS GERAIS, 2011c), há municípios que possuem a AFF, mas a ETE não foi implantada. Com isso, essa ETE que não existe, mas está regularizada ambientalmente, é considerada nos índices do PMTE, acarretando mais uma vez em valores 
discrepantes da realidade.

Já na bacia hidrográfica do rio Pará (BHRPA), também sub-bacia da BHSF, que abrange 35 municípios, constatou-se, com base nas informações declaradas pelos gestores municipais, que dos 650.891 habitantes que contribuem com o lançamento de esgotos na BHRPA, 16\% (106.805 hab.) têm acesso ao tratamento de esgotos, enquanto $84 \%$ (544.086 hab.) lançam o esgoto in natura nos cursos d'água ou em terrenos da bacia (MINAS GERAIS, 2012a).

De um modo geral, nos municípios da BHRPA observa-se a predominância dos sistemas constituídos por tanque séptico ou tanque séptico seguido de filtro anaeróbio com avaliação somente da eficiência de remoção da matéria orgânica (entorno de 30-35\%), sem levar em consideração outros poluentes como nutrientes e metais pesados.

Em relação à regularização ambiental das ETE em operação, observou-se que das 23 ETE em operação analisadas, quatorze (74\%) não possuem regularização ou estão com regularização vencida e apenas seis (26\%) possuem regularização ambiental. Ao avaliar a situação dos 29 municípios que contribuem com o lançamento de esgoto na BHRPA foi constatado que apenas quinze (52\%) cumprem o estabelecido na DN COPAM n ${ }^{\circ}$ 128/2008 (MINAS GERAIS, 2012a).

É importante ressaltar que o maior percentual de atendimento a DN COPAM n ${ }^{\circ} 128 / 2008$ na BHRPA ocorre para os municípios do Grupo 7 (menos populosos), visto que para estarem regularizados precisam apenas ter preenchido e enviado à FEAM o relatório técnico da situação do esgotamento sanitário do município, enquanto a implantação de ETE regularizadas pode ser concluída até março de 2017. Dessa forma, daqueles que pertencem ao Grupo 7, 61\% dos municípios estão regularizados, enquanto para os demais grupos apenas um (17\%) está de acordo com a DN 128/2008 (MINAS GERAIS, 2012a).

No que se refere à bacia hidrográfica do rio Piracicaba (BHRPI), localizada na bacia hidrográfica do Rio Doce, o enquadramento dos corpos d'água segundo classes, foi dividido em 78 (setenta e oito) trechos entre classes I e classe II (conforme Deliberação Normativa do COPAM n ${ }^{\circ}$ 09/1994). Entretanto, os levantamentos de campo demonstraram que existem muitos conflitos pelo uso da água em relação às classes de enquadramento. Tal fator é resultado do lançamento de esgoto doméstico, no qual houve desacordo com os limites legais em dez de treze estações de amostragem da qualidade da água (especificamente para o parâmetro de coliformes termotolerantes) nesta bacia hidrográfica.

Ressalta-se que existe desde o ano 2000 o Comitê de bacia (criado pelo Governo de Minas Gerais) e desde 2011 a Agência de Bacia (institucionalizada pela Agência Nacional de Águas). Apesar deste desenho institucional, percebe-se um peso enorme formado pela burocracia do Estado que não consegue resolver os problemas relacionados com as dificuldades de tratamento de esgoto nesta bacia. É importante observar que a meta de universalização de esgotamento sanitário não é atingida, pois a ação do saneamento básico não consiste somente em coletar o esgoto. Percebe-se que o grande objetivo do PMTE não é alcançado quando os dados de insalubridade ambiental vêm à tona, representados pela má qualidade da água identificada nos próprios relatórios da FEAM.

A BHRPI possui 859.740 habitantes (população urbana) e destes, 84,4\% lançam seus esgotos domésticos na bacia, sendo grande parte lançados in natura. Somente $39,9 \%$ da população urbana é atendida por serviços de tratamento de esgotos. Tal dado não reflete toda a bacia, pois o município de Ipatinga (município mais populoso) possui elevado percentual de tratamento de esgoto (98\%), enquanto entre os outros dezenove municípios que a bacia abrange quatorze não possui nenhum tratamento (MINAS GERAIS, 2013d).

Com relação à prestação dos serviços de esgotamento sanitário na BHRPI, percebe-se que as prefeituras são responsáveis por $70 \%$ dos municípios e população atendida de somente $16,4 \%$. Esses dados se invertem quando a COPASA é responsável pelo serviço, atendendo $20 \%$ dos municípios, porém com o atendimento de $59,7 \%$ de toda a população atendida da bacia. Tais números refletem que as políticas públicas de saneamento, especialmente de esgotamento sanitário, através do PMTE, seguiram uma definição de escolha racionalidade econômica, no qual prioriza-se que os serviços sejam prestados nos municípios com maior possibilidade de retorno financeiro à COPASA.

O panorama da situação das ETE na BHRPI demonstra que apenas 35,1\% delas estão em funcionamento, $21,6 \%$ estão fora de operação e $37,8 \%$ estão em fase de elaboração de projeto. Tais dados demonstram a ineficiência quanto à escolha de uma política pública voltada para a visão burocrática regulatória baseada no cumprimento de metas de licenciamento ambiental de ETE. 
Já com relação aos Planos Municipais de Saneamento Básico (PMSB), apenas dois municípios possuem este instrumento (MINAS GERAIS, 2013d). Tal informação demonstra que a BHRPI não está priorizando as diretrizes da Lei Federal $n^{\circ}$ 11.445/2007 que estabelece ser de responsabilidade do titular dos serviços a elaboração do PMSB e é condição de validade dos contratos que tenham por objeto a prestação de serviços públicos de saneamento. Tais municípios correm o sério risco de elaborar seus PMSB com rapidez sem considerar a necessidade de estabelecer processos participativos de elaboração e até mesmo, caso não venham elaborar seus planos nos prazos da Lei, não terem acesso aos recursos orçamentários da União para os serviços de saneamento básico.

No que se percebe, os PITE - Plano de Incremento do Percentual de Tratamento de Esgotos Sanitários - das bacias avaliam basicamente as características de manutenção e de operação das ETE e o estágio atual de regularização ambiental dessas estações nos municípios pertencentes às bacias englobadas pelos Planos. Dessa forma, apesar do crescimento da implantação de sistemas de tratamento de esgotos com regularização ambiental em Minas Gerais nos últimos anos e do atendimento de alguns municípios às metas do PMTE, alguns quesitos essenciais não foram considerados durante o processo de avaliação no âmbito do PMTE.

Dentre esses quesitos, o simples atendimento às metas de regularização ambiental do Programa não garante que o esgoto seja tratado da maneira adequada nas ETE, fazendo com que os efluentes finais possam ter baixa qualidade e continuem a poluir os corpos d'água receptores.

Outro quesito não considerado na metodologia de avaliação do Programa é a não realização do monitoramento da qualidade da água dos corpos receptores, fazendo com que o objetivo do Programa em reduzir a poluição hídrica nas bacias hidrográficas do Estado e, consequentemente, melhorar a qualidade de vida população, não seja analisado pelo PMTE.

\subsection{Correções de ações}

As ações de correções no ciclo de políticas envolvem um conjunto de alterações e prioridades definidas pela política e medidas de adaptação (SECCHI, 2010).

O relatório de progresso do ano de 2009 do PMTE mostrava ainda resultados insatisfatórios quanto à regularização ambiental dos sistemas de tratamento de esgotos. No entanto, poucas medidas corretivas ou adaptativas da política foram tomadas. O relatório, de maneira geral, sustenta que os valores e as vistorias analisadas apontaram para sistemas ainda pontuais, com problemas de operação e manutenção (MINAS GERAIS, 2010).

Alguns problemas foram identificados, como ETE licenciadas em que o esgoto não chega até a estação, e até mesmo casos de estações funcionando em perfeito estado e sem licenciamento. No relatório de 2009 foi constatada a existência de dados conflitantes entre a COPASA e o Governo Estadual, dentre eles se destacam: o número de ETE no Estado e o número de licenças e autorizações concedidas. Para ambos os problemas, observou-se que nenhuma medida foi tomada, pois nos relatórios dos anos seguintes a mesma questão é citada.

Em relação às ETE sem regularização ambiental, que não são contabilizadas, os relatórios do PMTE identificam o problema e constatam que essas ETE são irregulares e passíveis de atuação. Como forma de superar esse conflito foram estabelecidos prazos para a regularização de alguns sistemas de tratamento operando entre $60 \%$ e $80 \%$ da população urbana.

Outro ponto, com necessidade de melhoria, identificado pelo PMTE tem relação com a capacidade instalada e percentual de atendimento, pois nem todas as ETE operam com a sua capacidade máxima instalada. Porém não foi relatada nenhuma medida de correção nos relatórios seguintes. Além disso, pelos relatórios de progresso, verificou-se no PMTE pouco envolvimento dos usuários e falta de controle social. Como forma de enfrentar essa situação, o Programa promove capacitação dos usuários e mobilização do Estado para que seja cada vez maior a população urbana atendida por tratamento de esgotos.

\subsection{Sucessão e desativação}

O processo de sucessão de uma política pública pode ser entendido como medidas de continuidade a médio e longo prazo. Conjunto de ações que permitem a continuidade e a sustentabilidade do programa ou política de intervenção (SECCHI, 2010).

Já a desativação de um programa ou uma política pública pode ser entendida como o fim e/ 
ou o encerramento das ações de intervenção.

No PMTE, os processos demográficos e o crescimento da população não foram considerados no desenho e na implementação do Programa, sendo que estes podem influenciar a sucessão do Programa a médio e longo prazo.

Outro fator que pode influenciar a continuidade da ação a médio e longo prazo está relacionado à renovação das LO e AAF. Quanto a este ponto, verificou-se que no ano de 2012 diminuiu o percentual da capacidade instalada, na medida em que muitos municípios não renovaram as licenças para as ETE.

Em relação à desativação, O PMTE ainda está em andamento, tendo sido previsto o ano de 2017 para o seu encerramento. No entanto, existem dúvidas em relação ao cumprimento das metas estabelecidas (MINAS GERAIS, 2012b).

\section{CONSIDERAÇÕES FINAIS}

Constata-se certo negligenciamento de avaliação de políticas públicas em saneamento no Brasil, tanto no que se refere à ação do Estado quanto da própria pesquisa científica. No entanto, observa-se a necessidade de aprimorar e refinar diferentes modelos analíticos que superem a visão linear da ação governamental considerada "ideal", ou seja, onde correntes tradicionais não consideram o ciclo de políticas públicas como um processo.

Em contraposição a esta visão simplista de verificação da eficácia de programas governamentais, este trabalho focalizou uma abordagem mais ampla da implementação que enfatiza os elementos de aprendizagem, evolução, adaptação e a implementação como decisão política. Nesse sentido, ciclo de políticas públicas configura-se como um modelo analítico interessante, pois considera não somente a formulação como importante na definição da intervenção do Estado, mas reforça a perspectiva de implementação e avaliação das ações num contexto sistêmico.

Nesse sentido, não cabe aos autores deste trabalho propor melhoras ou recomendações ao Governo do Estado de Minas Gerais sobre a avaliação do Programa Minas Trata Esgoto, mas é importante ressaltar a necessidade de considerar os diferentes interesses dos atores sociais envolvidos no processo de implementação desta política pública com vistas a aprimorar a visão integrada de saneamento e tratamento de esgotos em suas diferentes interfaces com a saúde, meio ambiente, recursos hídricos, articulação institucional e a dimensão social.

\section{AGRADECIMENTOS}

Os autores deste trabalho prestam gratidão ao Professor Titular da Universidade Federal de Minas Gerais, Leo Heller, que também é Relator Especial da Organização das Nações Unidas para o tema da água e saneamento como direito humano, mandato de 2014 a 2016. O referido professor contribuiu com os autores no âmbito da disciplina Políticas Públicas em Saneamento do Programa de Pós-Graduação em Saneamento, Meio Ambiente e Recursos Hídricos da UFMG. Os autores também agradecem ao Conselho Nacional de Desenvolvimento Científico e Tecnológico, CNPq, à Coordenação de Aperfeiçoamento de Pessoal de Nível Superior, CAPES, pela concessão das bolsas de doutorado.

\section{REFERÊNCIAS}

ARRETCHE, M. Federalismo e Politicas Sociais no Brasil: problemas e coordenação e autonomia. São Paulo em Perspectiva, 18, 2: 17-26. 2004.

ARRETCHE, M. Federalismo e relações intergovernamentais no Brasil: a reforma de programas sociais. Dados, Revista de Ciências Sociais (Rio de Janeiro), v. 45, n³, p. 431 a 458, 2002.

BAPTISTA, T. W. F.; REZENDE, M. A ideia de ciclo na análise de politicas públicas. Site: http://www.ims.uerj. $\mathrm{br} / \mathrm{pesquisa/ccaps} /$ ? $=432.2011$. 
BELLONI, I. Metodologia de Avaliação em Politicas Públicas: uma experiência em educação profissional. São Paulo: Cortez, 2000.

BRASIL. Lei Federal n ${ }^{\circ}$ 11.445. Estabelece diretrizes nacionais para o saneamento básico. 05 de janeiro de 2007.

CASTRO, J. E. Políticas públicas de saneamento e condicionantes sistêmicos. In: HELLER, L.; CASTRO, J.E. Política pública e gestão de serviços de saneamento. Belo Horizonte: Ed. UFMG; Rio de Janeiro: Ed. Fiocruz, 2013. P. 53-75.

CAVALCANTI, Mônica Maria de Arruda . Avaliação de políticas públicas e programas governamentais - uma abordagem conceitual. Interfaces de Saberes (João Pessoa), v. 6, p. 1-13, 2006.

COHEN, E; FRANCO, R. Avaliação de Projetos Sociais. Petrópolis, Vozes, 2004.

COSTA, F. L.; CASTANHAR, J. C. Avaliação de programas públicos: desafios conceituais e metodológicos. Revista de Administração Pública, Rio de Janeiro, v. 37, n. 5, p. 969-992, 2003.

CUNHA, C. G. S. Avaliação de Politicas Públicas e Programas Governamentais: tendências recentes e experiências no Brasil. George Washington University. 2006.

HELLER, L., CASTRO, J. E. Política pública de saneamento: apontamentos teórico-conceituais. Engenharia Sanitária e Ambiental, v. 13, n.3, p. 284-295, 2007.

HELLER, L.; BRAGA, R.; RODRIGUES, L.; LISBOA, S. Planejamento em saneamento básico. In: Heller, L. Saneamento básico, saúde ambiental e políticas públicas. Novos paradigmas para a América Latina e Caribe. Washington DC: Pan-American Health Organization. 2012.

HOGHOOD, B.; GUNN, L. Policy analysis for the real world. Oxford: Oxford University Press. 1984.

KERBAUY, M. T. M. Descentralização, formulação e implementação de Politicas Públicas. Ciência Política, Site, 2002. Descentralização, processo decisório e politicas públicas locais. Estudos de Sociologia (São Paulo), Araraquara, v. 16, p. 151-166, 2004.

KINGDON, John. Agendas, Alternatives, and Public Policies. Boston: Little, Brown. 1984.

LOWI, Theodor. Four Systems of Policy, Politics, and Choice. Public Administration Review, 32: 298-310. 1972.

LOWI, Theodor. American Business, Public Policy, Case Studies and Political Theory, World Politics. 16: 677-715. 1964.

MENEGUIN, F. B.; FREITAS, I. V. B. Aplicações em avaliação de politicas públicas: metodologia e estudos de caso. Brasília. 2013.

MINAS GERAIS. Companhia de Saneamento de Minas Gerais. Disponível em: <http//www.copasa.com. br//>. Acesso em: 07 de Novembro de 2013. (c)

MINAS GERAIS. Deliberação Normativa ${ }^{\circ}$ 128. Altera prazos estabelecidos pela Deliberação Normativa COPAM 96/2006 que convoca municípios para o licenciamento ambiental de sistema de tratamento de esgotos e dá outras providências. 27 de novembro de 2008.

MINAS GERAIS. Deliberação Normativa ${ }^{\circ}$ 96. Convoca municípios para o licenciamento ambiental de sistema de tratamento de esgotos e dá outras providências. 12 de Abril de 2006.

MINAS GERAIS. Fundação Estadual de Meio Ambiente. Plano para Incremento do Percentual de Tratamento de 
Esgotos Sanitários na Bacia Hidrográfica do Rio Paraopeba. Belo Horizonte. 2011. (c)

MINAS GERAIS. Fundação Estadual de Meio Ambiente. Plano para Incremento do Percentual de Tratamento de Esgotos Sanitários na Bacia Hidrográfica do Rio Pará. Belo Horizonte. 2012. (a)

MINAS GERAIS. Fundação Estadual de Meio Ambiente. Relatório de Progresso de 2009. Belo Horizonte. 2010.

MINAS GERAIS. Fundação Estadual de Meio Ambiente. Relatório de Progresso de 2010. Belo Horizonte. 2011. (a)

MINAS GERAIS. Fundação Estadual de Meio Ambiente. Relatório de Progresso de 2011. Belo Horizonte. 2012. (b)

MINAS GERAIS. Fundação Estadual de Meio Ambiente. Relatório de Progresso de 2012. Belo Horizonte. 2013. (b)

MINAS GERAIS. Fundação Estadual do Meio Ambiente. Plano para incremento do percentual de tratamento de esgotos sanitários na Bacia Hidrográfica do Rio Piracicaba: sumário executivo / Fundação Estadual do Meio Ambiente. - Belo Horizonte: FEAM, 2013. (d)

MINAS GERAIS. Fundação Estadual do Meio Ambiente. Plano para Incremento do Percentual de Tratamento de Esgotos Sanitários na Bacia Hidrográfica do Rio das Velhas. Belo Horizonte: FEAM. 2011. (b)

MINAS GERAIS. Os caminhos da Estrada Real. Disponível em <http://www.mg.gov.br/governomg/portal/c/ governomg/conheca-minas/turismo/5680-estrada-real/26677-estrada-real/5146/5044>. Acesso em: 11 de Novembro de 2013. (a)

NAJAN, A. Learnin from the Literature on Policy Implementation: A Synthesis Perspective. (Working Papers). International Institute for Applied Systems Analysis - IIASA. A-2361 Luxwnburg. Austria. 1995.

OLIVEIRA, J.A.P. Desafios do planejamento em politicas públicas: diferentes visões e práticas. Revista de Administração Pública, Rio de Janeiro, 40 (273-88), 2006.

SECCHI, L. Politicas Públicas: Conceitos, Esquemas de Análise, Casos Práticos. São Paulo: Cengage Learning, 133 p. 2010.

SOUZA, C. Políticas Públicas: uma revisão da literatura. Sociologias. Porto Alegre. 2006. 